\title{
O professor-designer de experiências de aprendizagem: autoria docente e uso de recursos lúdicos na formação de professores
}

\author{
Bianca Martins (UniCarioca | NUCAP | PUC-Rio) \\ Leonardo Nolasco-Silva (UERJ)
}

\begin{abstract}
Resumo
O artigo discute a preparação e a vivência de uma prática lúdica de ensinoaprendizagem elaborada em parceria por uma designer e um professor regular do curso de Pedagogia. Tal experiência foi produzida/ aplicada no contexto de uma disciplina do curso de Pedagogia da UERJ. A imersão no curso em questão fez parte de uma pesquisa mais ampla que visava compreender os benefícios do uso de recursos do Design (linguagem visual, processo projetual, processo criativo, configuração de artefatos e mediação cultural, etc.) na formação de professores. A experiência da imersão em um ambiente com sujeitos e situações específicas proporcionou um rico aprendizado e uma perspectiva crítica contextualizada pela experiência vivida. Participar do planejamento ousado de uma disciplina da Pedagogia e implementá-la com o professor, conviver com os futuros docentes e partilhar de suas inquietações e esperanças possibilitou a revisão de conceitos a respeito da relevância da aprendizagem do Design na formação de professores. O resultado da vivência põe em evidência os benefícios do uso de estratégias lúdicas de aprendizagem que respeitam diferenças e preferências como forma de atrair a atenção e a motivação dos estudantes para o conhecimento construído.
\end{abstract}

Palavras-Chave: Design; práticas pedagógicas; formação de professores; cotidiano escolar; currículo.

\begin{abstract}
This paper discusses the preparation and the experience of a playful practice of teaching and learning developed in partnership by a designer and a regular teacher of the Pedagogy course. This experience was produced / applied in the context of a Pedagogy course in UERJ. The immersion in this course was part of a broader research aimed at understanding the benefits of the use of Design resources (visual language, design process, creative process, artifact configuration and cultural mediation, etc.) in teacher training. The experience of immersion in an environment with specific subjects and situations provided a rich learning and a critical perspective contextualized by the lived experience. Participating in the daring planning of a Pedagogy discipline and implementing it with the teacher, living with the future teachers and sharing their concerns and hopes enabled the revision of concepts regarding the relevance of learning Design in teacher education. The result of the experience highlights the benefits of using playful learning strategies that respect differences and preferences as a way to attract students' attention and motivation to the knowledge construction.
\end{abstract}

Keywords: Design; pedagogical practices; teacher education; school daily; curriculum.

\section{Introdução}

No campo do Design, há alguns anos, discute-se que os conhecimentos próprios desta área são relevantes para um espectro de ações mais amplo do que o rotineiramente praticado/difundido. Segundo Lawson (2011), os designers operacionalizam seus projetos conciliando informações variadas e desconexas, conjugando necessidades de diferentes atores, trabalhando em equipe, etc. Tal forma de conduzir teria muito a acrescentar em campos que ultrapassam o escopo restrito dos projetos de Design, servindo também para pensar problemas da vida contemporânea. O Design proporia, pois, um jeito de olhar. 
Para Martins (2016), existe uma relação entre os princípios do Design e as demandas da escolarização formal, o que nos leva a pensar na pertinência da construção de pontes entre um campo e outro. Os princípios, metodologias, interações e práticas do Design podem servir à educação como estratégia projetual integradora de conhecimentos multidimensionais. Além disso, o 'pensar junto' do Design poderia aproximar professores e estudantes em torno de problemas comuns que, mais do que soluções, demandam formas variadas de abordagem. O Design, nesta direção, seria um modo de fazer perguntas, de rabiscar mapas e atualizar currículos, transformando os atores da sala de aula em roteiristas da própria experiência educativa.

Fazedores de mapas, professores e estudantes, vistos desta maneira, roteirizam aulas que inventam outros professores e estudantes. Todos praticantes (CERTEAU, 1994), percebidos em atos, operando lógicas que diversificam a formação. Tal como o filme que inventa o espectador ou o livro que cria o leitor, a aula inventa o estudante, o professor, a escola e a universidade. Dito isto, assumimos que não trabalhamos com a ideia de um professor e de um estudante constituídos por matéria própria e definitiva. Quando pensamos nesses sujeitos, nós os concebemos em movimento, performando nos cenários da educação formal de modo a atualizar as concepções de escola, universidade e afins.

Um currículo é, então, elaborado por múltiplos autores, dando vida a invenções humanas cujas tessituras em redes são ingovernáveis, imprevisíveis, impuras e incontroláveis. Se, por um lado, reconhecemos o currículo como parte integrante da "arte de governar", percebendo-o como espaçotempo que compõe um campo de formulações e práticas educativas que articulam interesses de diversos grupos sociais, por outro lado devemos entender que é necessário problematizar as formas como os praticantes (CERTEAU, 1994) jogam com essa engrenagem e a movimentam. Apesar da aparente força hierárquica dos planejamentos e metas curriculares, é na vida das escolas (e das universidades) que são tecidos os processos pedagógicos cotidianos.

Os currículos, deste modo, são produzidos nas escolas, por criações próprias e por influência de múltiplas forças sociais. Os currículos não são apenas reativos às determinações externas - como as políticas de Estado, por exemplo -, mas sim um jogo de negociações e de disputas que ocorrem localmente, em cada unidade escolar/acadêmica, no dentrofora das instituições, numa trama forjada por várias redes educativas que fazem de nós o que somos, o que estamos sendo e o que podemos vir a ser.

Partindo dessas noções, inspirados também em Kastrup (2005), acreditamos que a invenção de um curso inventa também os sujeitos que passarão a viver experiências nos espaçostempos por ele criados. Trata-se, também, do processo de atualização da ementa oficial que, como sabemos, possui uma história e nenhuma garantia de durabilidade para além dos cenários que lhe serviram de contexto no momento da sua criação. Portanto, a cada novo curso a ementa se renova, busca identificar o seu público, cria caminhos e possibilidades de diálogo na tentativa de convencer os estudantes de que caberá a eles a coautoria das aulas ministradas/vividas/fabuladas em dias e horários específicos, mas que transbordarão nos corredores, na Internet, nas mensagens de whatsapp que procuram definir/organizar, por exemplo, as ações a serem realizadas nos trabalhos em grupo.

Ao mesmo tempo em que nos inventamos como professores enquanto definimos o roteiro de um curso, queremos que os estudantes se reinventem nos processos das aulas, mas sabemos que isso depende também deles, do engajamento e da vontade de fazer junto, de comprar a ideia e de fazê-la sua, para além dos ritos acadêmicos protocolares (frequência, realização de tarefas, provas, etc).

Podemos dizer que tanto a educação quanto o Design só se realizam a contento quando há engajamento daqueles que os viabilizam. Engajamento que também é reconhecimento do público, dos seus desejos, das suas habilidades e, sobretudo, criação de espaçostempos de discussão, de ouvir o outro e produzir sentidos.

O Design, assim concebido, representa um tipo especial de aprendizagem ativa, aproximando-se das práticas educativas adiante elencadas. Seus princípios, como já salientado, favorecem uma abordagem multidimensional, o trabalho em equipe, a cooperação com o usuário, a interdisciplinaridade, a atenção sensível e o senso estético. Ao apontarmos tais questões, específicas do campo do design, desejamos inserir neste rol parte do que pensamos ser possível construir na educação, através daquele a quem chamamos 'professor designer de experiências de aprenderensinar' - ou, simplesmente, professor fazedor. 
Entendemos que os praticantes da sala de aula - estudantes e professores - não são meros receptores de serviços, produtos e estratégias pensadas por um profissional solucionador de problemas. Ao contrário, eles são parte dos problemas e das soluções, pois operam com suas trajetórias, seus saberesfazeres, suas práticas, seus corpos e ideias. Um designer que pretende atuar no campo da educação precisa levar em conta esse background dos praticantes da sala de aula, trabalhando sempre em parceria, adaptando, ressignificando, bricolando dinâmicas e materiais nos movimentos cotidianos dos cenários educativos.

Assim, o que discutimos aqui são as possibilidades de diálogo entre Educação e Design, não na perspectiva das ferramentas que um campo pode emprestar ao outro, mas sim na defesa do encontro de saberesfazeres distintos que formam outros tantos fazeressaberes que potencializam a construção coletiva dos conhecimentos em sala de aula e para além dela.

Nas pesquisas nos/dos/com os cotidianos, buscamos oportunizar movimentos de antidisciplina, contra a hierarquização dos fazeressaberes e em oposição à marginalização/exclusão que uma hierarquização promove. Desejamos um movimento dinâmico, aberto, cambiante e em constante ação-reflexão-ação, que assume os riscos, as incertezas e os acasos no seu tatear, em conexão com a vida, no tempoespaço em que ela pulsa e se transforma. Tal movimento se pauta no reconhecimento da complexidade, do que é tecido junto (MORIN, 2007) e na emergência de possibilidades.

\section{Preparação}

Um dos autores deste texto, docente regular da graduação em Pedagogia da UERJ, após ter conhecimento da pesquisa a respeito do Design em práticas de ensinoaprendizagem, pesquisa esta que estava em andamento em decorrência de um estágio de doutoramento em Design (PUC-Rio 2012/2016), convidou a outra autora deste texto para preparar e implementar com ele uma disciplina no curso em questão. Tratava-se da disciplina Tópicos Especiais II - Metodologias na produção de meios e recursos educativos, ministrada no segundo semestre (agosto a dezembro) de 2015, às quartas-feiras, das 18h às 19h30min. Quarenta alunos estavam matriculados na disciplina. Para dar conta da empreitada, nos encontramos, durante o mês de julho de 2015, para ajustar os objetivos da experiência conforme alguns pressupostos.

Partimos da premissa de que nossa tarefa estaria muito além de ensinar a usar tecnologias digitais para a produção de meios e recursos educativos, como vinha sendo feito nos últimos semestres por outros professores que ministraram a disciplina. Nossa proposta era discutir e praticar a linguagem e a produção de recursos educativos, questão que em nosso entendimento seria mais ampla do que trabalhar apenas os recursos digitais na educação. Debatemos ideias e propostas durante algumas semanas e por fim chegamos a uma proposição. Nossa intenção passou a ser vivenciar com os estudantes uma situação lúdica que favorecesse discussões e aprendizados. Esta situação lúdica requisitaria dos estudantes, organizados em grupos, a solução de um mistério - algo que despertasse a atenção, propiciasse engajamento e abrisse um leque de temas sociais que seriam, em última instância, o mote para a realização da disciplina. Pretendíamos com isso sublinhar que os recursos educativos criados pelo professor-designer-de-experiências deveriam partir das realidades locais, das situações vivenciadas pelos praticantes da sala de aula, de modo que a vivência oportunizada pelo recurso seja significativa e produtora de sentidos múltiplos por cada um dos participantes.

Tal empreitada demandaria o desenvolvimento de uma estratégia/objeto para comunicar a certo grupo de pessoas um determinado assunto/situação. Assim, precisávamos inventar algo que instigasse a participação ativa do aluno na solução de um mistério/problema e mais: deveríamos fazer essa produção pensando em um público específico - estudantes adultos, com diferentes idades e trajetórias, a maioria composta por trabalhadores que estudam à noite e que, portanto, chegam à universidade com o cansaço de um dia de trabalho. Caberia aos educadores-designers-de-experiências planejar algo que se adequasse ao perfil deste público e que, ao mesmo tempo, viabilizasse o programa da disciplina.

Abaixo alguns parâmetros do curso e anotações do nosso Diário de Bordo quanto ao planejamento da disciplina.

- Objetivo: aprender por meio de recursos lúdicos e desenvolver um material/artefato com linguagem visual adequada ao público. 
- Encontros: 15 encontros.

- $\quad$ Metodologia e recursos didáticos: jogar, discutir achados de cada fase do jogo; projetar artefato.

- Avaliação: autoavaliação, frequência e performance, desempenho no projeto final.

\begin{tabular}{|l|l|}
\hline Data & \multicolumn{1}{c|}{ Anotações } \\
\hline $\mathbf{1 7 / 0 7}$ & $\begin{array}{l}\text { Encontro na Confeitaria Colombo. } \\
\text { Ficou definido que a dinâmica do curso estaria baseada } \\
\text { cotidiano e, em seguida, seria discutida uma solução } \\
\text { para ele por meio dos recursos da Aprendizagem Ba- } \\
\text { seada em Design. }\end{array}$ \\
\hline $\mathbf{2 0 / 0 8}$ & $\begin{array}{l}\text { A designer devolve ao professor um roteiro de aula pro- } \\
\text { pondo atividades práticas e textos para cada aula. } \\
\text { O professor diz que tem uma nova proposta que envolve } \\
\text { o uso de estratégias do RPG }\end{array}$ \\
\hline $\begin{array}{l}\text { E) } \\
\text { e diferença no contexto escolar. } \\
\text { A turma será dividida em quatro grupos: professores, } \\
\text { pais, alunos e gestão escolar. Cada grupo vai encontrar } \\
\text { formas de entender e enfrentar problemas relativos à } \\
\text { diversidade na escola. } \\
\text { Decidimos que o Design entra para ajudá-los a entender } \\
\text { como desenvolver uma abordagem apropriada para abor- } \\
\text { dar cada situação/público. }\end{array}$ \\
$\begin{array}{l}\text { O professor conta detalhadamente sua proposta de RPG. } \\
\text { A princípio, a designer a achou muito confusa. } \\
\text { Haverá uma narrativa com um mistério a desvendar. } \\
\text { A narrativa estimula a abordagem da questão Identidade }\end{array}$ \\
\hline
\end{tabular}

Tabela 1: Diário de Bordo sobre o planejamento da disciplina.

Ao longo do mês de julho, foi desenvolvida uma narrativa de suspense que envolveu cenários, tabuleiro e uma série de personagens. Ou seja, coube ao professor construir as bases concretas (confeccionou o tabuleiro e adquiriu personagens) e a narrativa de um jogo que chamou de O que não tem governo nem nunca terá. Em nossas conversas e reuniões de trabalho, tivemos alguma clareza sobre a viabilidade do projeto e fomos amadurecendo a ideia do que seria um professor-designer de experiências de aprendizagem - alguém que demonstra envolvimento com o tema a ser trabalhado, que produz uma narrativa e objetos bastante originais e possui motivação para superar expectativas e adversidades. 


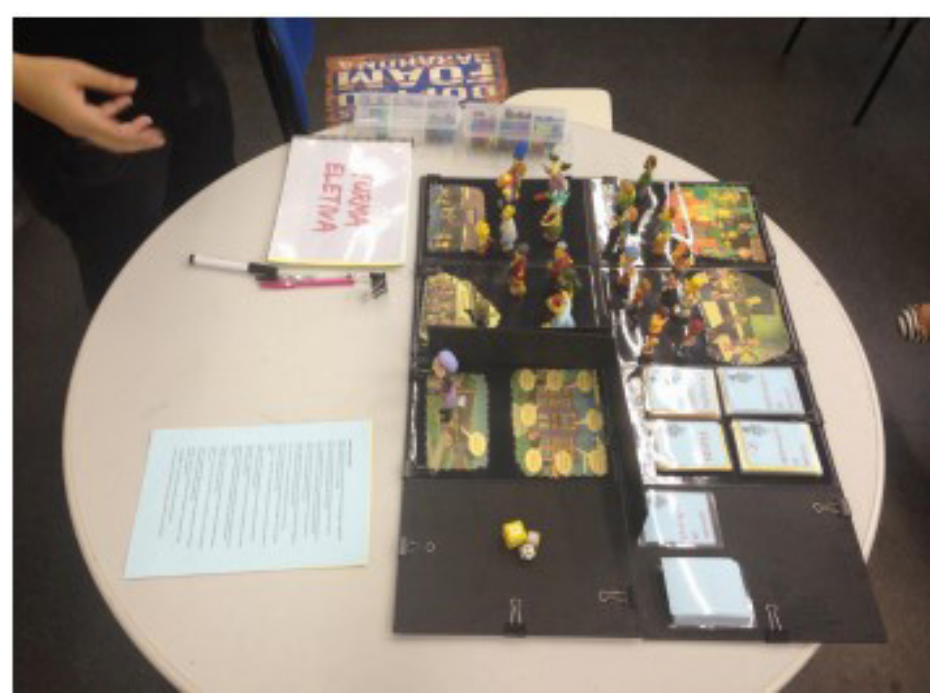

Figura 1: Imagem do jogo sendo usado em sala de aula.

Sobre os encaminhamentos do jogo podemos dizer, de forma resumida, que o ponto de partida foi o desaparecimento de um aluno, pré- adolescente, chamado Cristiano. Ele tinha ido a um passeio de fim de semana organizado pela escola, mas não havia retornado com os demais colegas. Assim, o mote das partidas seria descobrir o que aconteceu com o Cristiano e, para isso, a turma se dividiu em quatro grandes grupos: um grupo de professores representados pela professora Edna; um grupo de estudantes encabeçado pela aluna Meg; um grupo de pais e responsáveis, cuja protagonista era a mãe de uma estudante chamada Luiza e um grupo que representava a direção da escola, liderado pelo diretor Nelson. As ações de cada um desses quatro personagens tinham como intenção descobrir o paradeiro de Cristiano, porém, na execução das partidas, eles se deparavam com temas polêmicos muito comuns no cotidiano das escolas - homofobia, racismo, intolerância religiosa, bullying, distúrbios alimentares, violência doméstica, etc. Esse leque de temas, pensados a partir do conceito de diferença (na perspectiva deleuziana) possibilitou a criação de situações pedagógicas em que a produção material das aulas dialogava com problemas reais, ainda que simulados em um jogo de tabuleiro.

\section{Público}

Sobre o público, como já salientado acima, tínhamos uma presença majoritária de mulheres, trabalhadoras, moradoras das periferias da cidade, um número considerável de mães, com diversidade de idades e que se declaram, em sua maioria, evangélicas. É importante citar esse perfil porque ele coloca para o professor alguns desafios:

- $\quad$ Os jogos de RPG não são muito comuns entre mulheres (nem entre as classes populares);

- $\quad$ Estudantes trabalhadoras e mães têm, pelo menos, uma tripla jornada - no emprego, na universidade e em casa - chegam cansadas nas aulas e precisam ser motivadas;

- A questão religiosa poderia ser um problema diante dos temas trabalhados, sobretudo os que falavam de gênero e sexualidade.

O conceito de praticantes, pinçado na obra de Certeau (1994), deixa clara a ideia de ação a partir da qual 
pensamos os estudantes - eles não são indivíduos isolados aptos a receber mensagens, mas criadores ativos capazes de receber-emitir-bricolar-inventar-atualizar pensamentos e atitudes, sem necessariamente abrir mão dos seus acúmulos culturais, pois existem no dentrofora da universidade, transitam por cenários carregados de memórias, saberesfazeres e singularidades, traços que sofrem severas tentativas de silenciamento no meio acadêmico, lugar de uma suposta neutralidade, objetividade e assepsia teórico-metodológica.

\section{Metodologia}

Nosso primeiro desafio metodológico foi criar um sistema de RPG que oportunizasse a construção de uma história que nos mobilizasse e permitisse debater os temas da disciplina. Deveria ser um jogo de brincar de ser levado a sério, algo que criasse um mistério capaz de manter a nossa atenção ao longo de um semestre. Sabíamos que era próprio do RPG surpreender os jogadores, criando entrechos que mudam personagens de lugar, obrigando-os a rever suas estratégias e isso era um trunfo que tínhamos para criar situações diferentes em cada aula, inserir novos personagens e, por consequência, novos temas. O Mestre de RPG precisa ter sensibilidade para perceber quando o jogo fica morno e, quando isso acontece, cabe a ele propor acontecimentos que estimulem os jogadores a recuperar o entusiasmo (qualquer semelhança com o ofício do professor será mera coincidência?).

Decidido o jogo, passamos para a definição dos personagens (não de suas características comportamentais ainda, mas sim de sua imagem). Acreditávamos que seria mais estimulante jogarmos com avatares conhecidos, bonecos que habitassem nossas memórias e que criassem com cada jogador uma identificação para além do jogo.

Considerando as opções existentes no mercado (em variedade de modelos e bom preço) escolhemos montar o nosso sistema com os personagens de Os Simpsons - conhecido por ser um desenho animado para adultos. Tomada a decisão, os bonecos foram garimpados na Internet, na Feira da Praça XV (no Rio de Janeiro) e na Galeria dos Brinquedos (em São Paulo). A busca durou o recesso de julho/agosto e iniciamos o segundo semestre de 2015 já com o sistema definido.

Para confeccionar o tabuleiro usamos papel Paraná (chamado de holler em alguns lugares). Pensando na locomoção, testamos maneiras de dobrar o material de forma que coubesse na mochila sem danificar a estrutura. Ao invés de cenários fixos, colados ou desenhados no tabuleiro, produzimos fichas grandes e as plastificamos. Elas deveriam ser montadas como um quebra-cabeças sobre o tabuleiro, presas por grampos metálicos. Dessa forma, seria possível mudar os cenários rapidamente, sempre que se fizesse necessário.

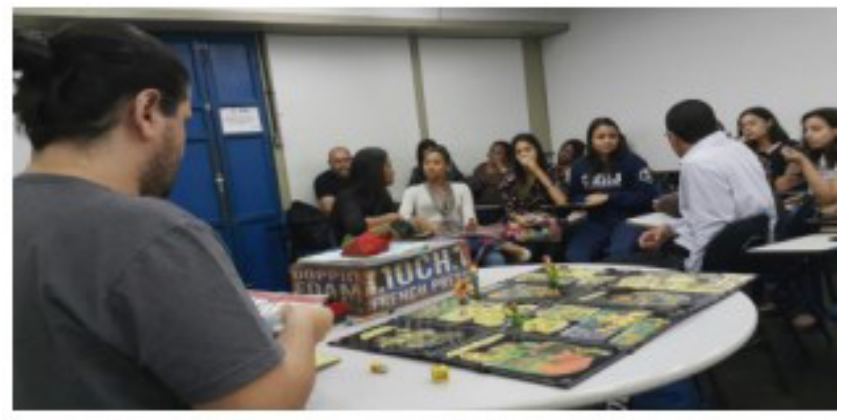

Figura 2: Tabuleiro de RPG produzido para as aulas. Preparação de uma partida realizada na disciplina Metodologias na produção de recursos e materiais educativos. $2015 / 2$. 
Foram criadas também cartas de personagens em papel vergê de $180 \mathrm{~g}$, devidamente plastificadas para garantir a durabilidade. Nessas cartas estão dispostos sistemas de pontuações prévias que ajudam a definir as possibilidades de locomoção dos personagens no tabuleiro.

Os valores das cartas são confrontados com a sorte dos dados, e os jogadores se movimentam conforme esse conjunto de definições. No movimento, para além da sorte de cada participante, há uma ação estratégica visando determinado fim. Por exemplo: Eu quero mandar a professora Edna para o cemitério e jogarei por ela na próxima rodada.

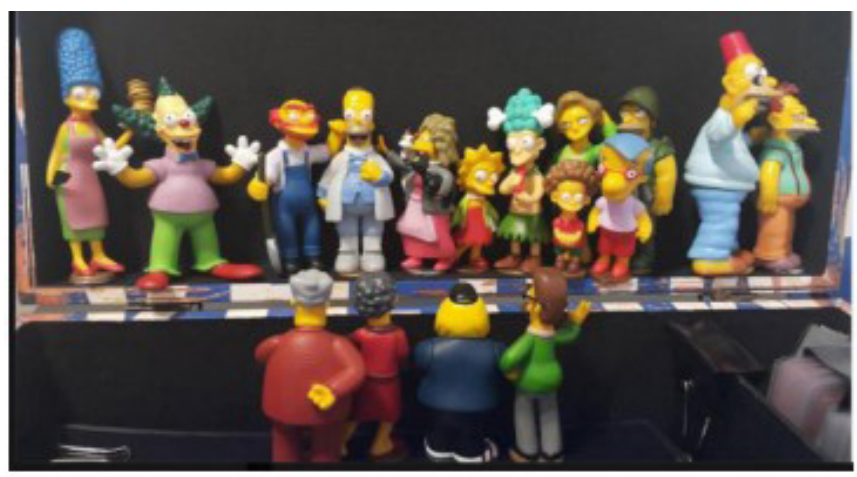

Figura 3: Personagens do jogo.

Além do tabuleiro, dos avatares e das cartas, esse sistema de RPG também conta com dados de 6 e 20 lados, responsáveis por determinar algumas tarefas em cada rodada. Os dados foram customizados para o jogo.

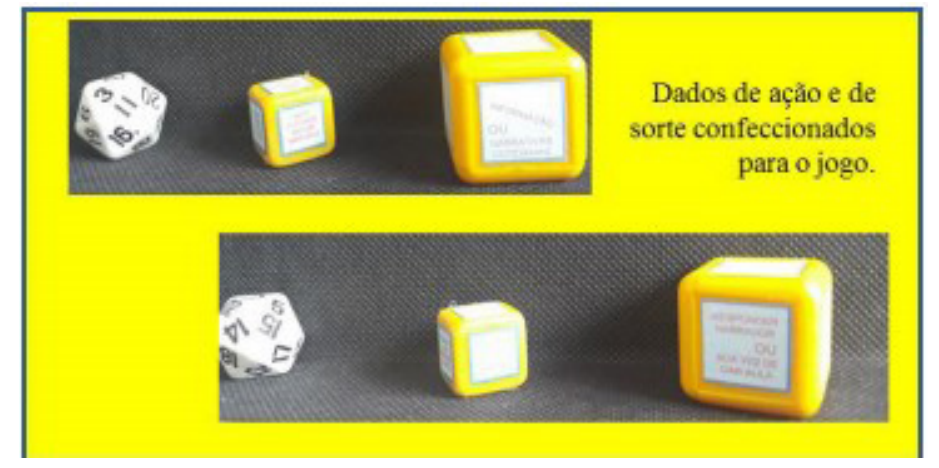

Figura 4: Dados produzidos para o jogo.

Mas, como jogar uma partida de RPG com mais de 40 estudantes? Esse foi outro desafio. Manter alguma organização em um grupo tão grande e diverso exigiu que pensássemos juntos alguma alternativa que, associando pessoas em grupo, permitisse que todos participassem ativamente no desenrolar das partidas (o que não garante que todos irão participar, mas, se quiserem, poderão). 
Como a história do sistema criado deveria ter por cenário uma escola, construímos, como citado, quatro tipos de personagens principais: estudante, diretor/a, professor/a e responsável. Cada um desses arquétipos ficaria sob a condução de um grupo de dez estudantes - grupos formados por adesão (alguns grupos ficaram com mais de dez integrantes). Assim, criamos Meg (a estudante), Nelson (o diretor da escola), Edna (a professora) e Luiza (a mãe de um aluno). Esses quatro personagens ganharam matizes diferentes em cada grupo e suas trajetórias mimetizavam comportamentos comuns aos integrantes de cada equipe. Para o grupo com mais estudantes religiosas, por exemplo, Luiza era uma espécie de beata; para o grupo de estudantes mais jovens ela tinha um caso com o diretor Nelson.

Vale ressaltar que as ações dos personagens no tabuleiro contribuíram para a construção coletiva da história principal e, não raras vezes, os grupos se acusavam por identificar alguém que tinha culpa no cartório, isto é, que tal personagem estaria envolvido no sumiço de Cristiano.

Basicamente, em todas as aulas houve uma rodada do jogo em que os quatro personagens se movimentavam e recebiam pistas sobre o mistério. As pistas eram cartas escritas pelo professor, que continham um forte apelo à discussão de problemáticas de gênero, bullying de diversas formas, papel da mulher, questões de poder, alteridade e subjetividade no contexto escolar, dentre outras questões sutis que aparecem a partir da convivência em sala de aula.

A partir de determinadas questões, encaminhávamos a discussão para a produção de materiais e recursos didáticos, valorizando o papel do professor como um designer de experiências de aprendizagem.
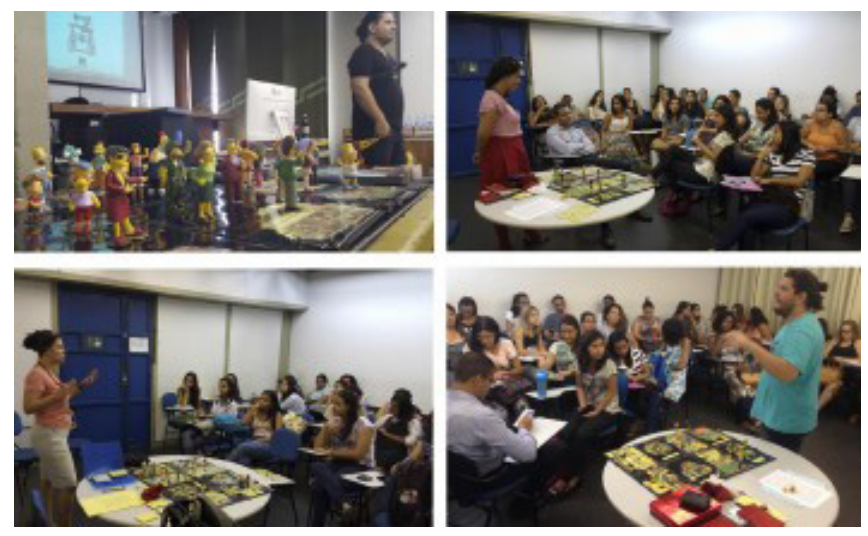

Figura 5: Imagens das partidas jogadas em contexto de sala de aula.

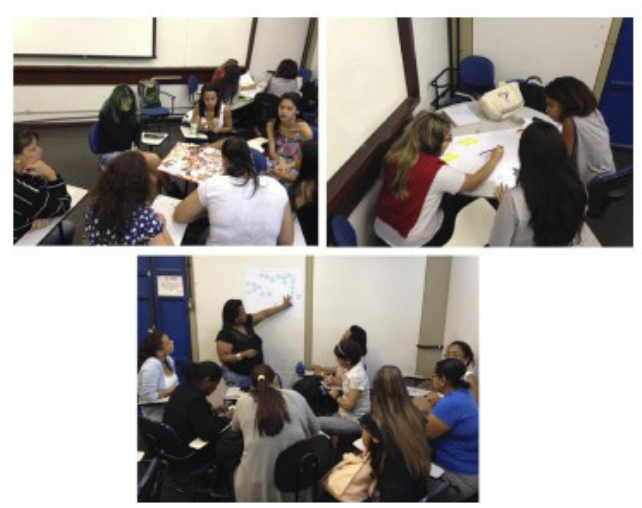

Figura 6: Imagens das partidas jogadas em contexto de sala de aula. 


\section{Estratégias e recursos utilizados}

Optamos por realizar a disciplina com o recurso de múltiplos meios. Durante as aulas, foram usados recursos analógicos (cenário, personagens, cartas, etc.), lemos e discutirmos textos. Utilizamos também outros recursos, como aulas expositivas, filmes, músicas, dentre outros.

Sobre as estratégias de comunicação, lançamos mão das redes sociais para motivar os grupos e instigar a solução do mistério durante o período fora de sala de aula. Um grupo no Facebook com todos os alunos da turma foi criado para tal.

Usamos, ainda, estratégias próprias do Design para ajudar a turma a trabalhar no desenvolvimento de um artefato de comunicação focado em linguagem visual e estratégias específicas para atingir um determinado público: trabalhamos com mapas conceituais, moodboards, geração de alternativas e orientação aos grupos através do olhar do Design.

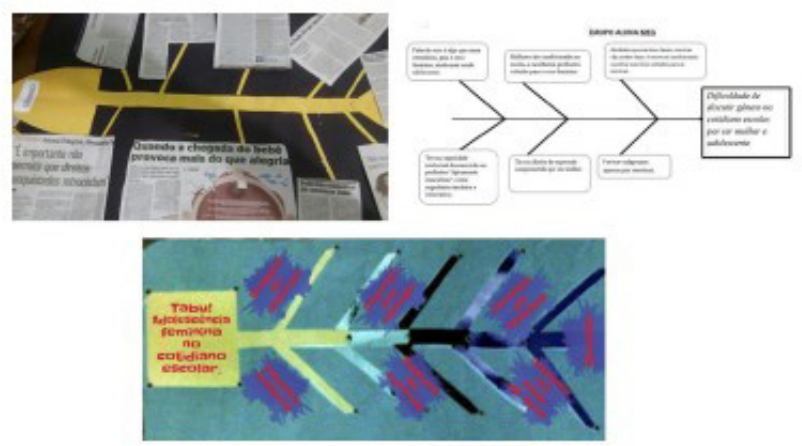

Figura 7: Imagen com alunos discutindo e desenvolvendo os projetos conforme as técnicas aprendidas.

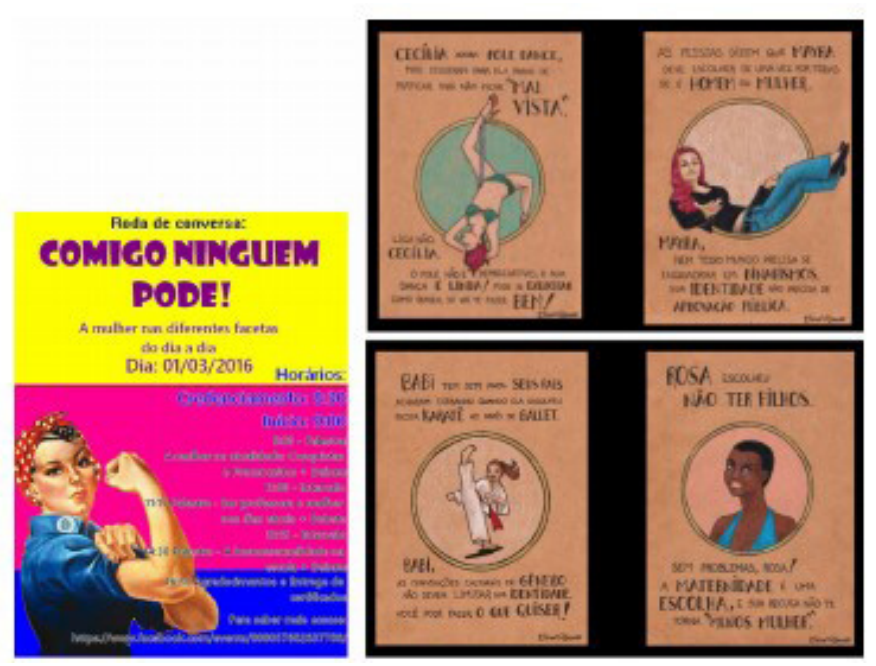

Figura 8: Alguns resultados que exploraram recursos visuais para impactar o público a respeito de uma situação indesejada. 

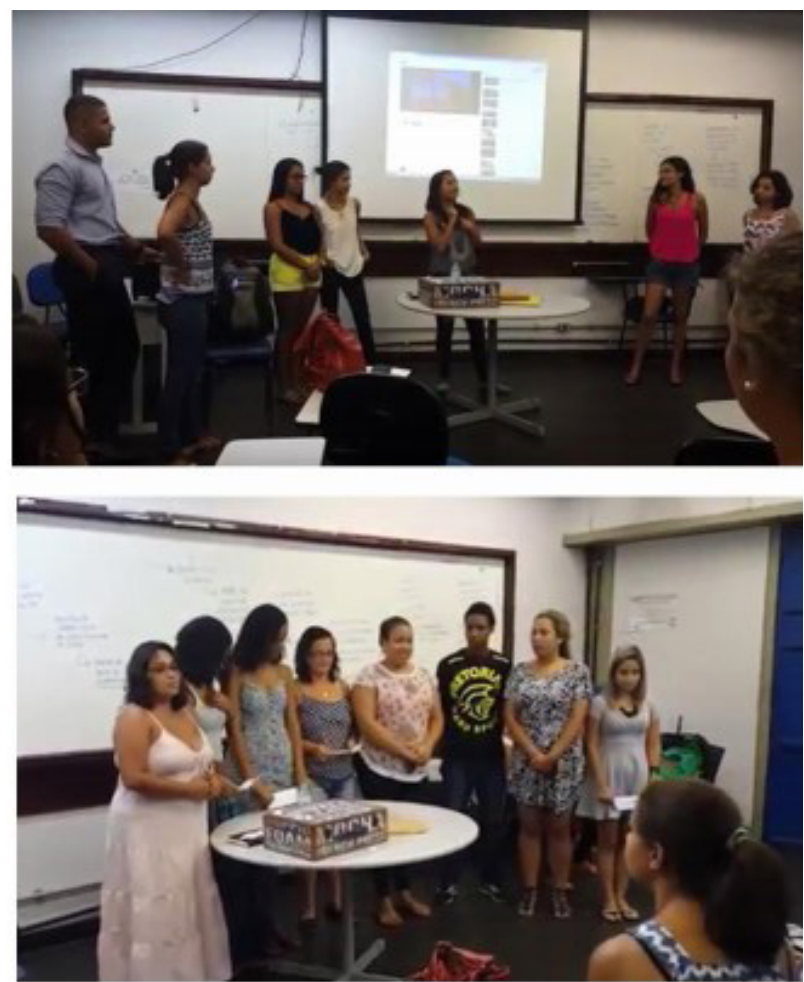

Figura 9: Alguns resultados que exploraram estratégias dinâmicas para impactar o público a respeito da situação indesejada.

\section{Resultados}

As atividades narradas mostraram-se bem sucedidas em seus objetivos. Foi uma vivência muito intensa, uma vez que os alunos se engajaram muito à proposta apresentada, trazendo semanalmente ideias para solucionar o mistério. Tais movimentos exigiram uma constante reformulação da história, porque dados novos (produzidos pela turma) precisavam se integrar à narrativa inicial, amarrando cenas, personagens, temas e conceitos caros à disciplina. A vivência com diferentes materiais e a possibilidade de criar nossos próprios objetos de aula oportunizaram um entendimento da viabilidade do professor - autor, criador de situações que estimulem não só a turma, mas a si mesmo. Quanto às estratégias didáticas, cremos que ficou claro que a ousadia instiga professores e alunos a superar expectativas. Foi uma meta-aprendizagem: enquanto discutíamos novas possibilidades didáticas, estávamos jogando e vivenciando personagens, cenários, discursos e desenvolvendo objetos para dar conta do desafio proposto.

Um ponto nos marcou especificamente: percebemos que os termos Design ou Designer assustavam e repeliam o público nas vezes em que foram utilizados. Tentamos explicar e fizemos até mesmo uma apresentação procurando desmitificar a questão, mostrando que todos eles eram um pouco Designers, pois preparavam materiais didáticos para seus alunos, mas não funcionou. Para contornar a situação, passamos a trabalhar sem usar estes termos, substituindo-os por projeto, estratégia criativa, processo projetual, projetista, etc. Com isso, conseguimos evitar ruídos e engajar melhor os pedagogos às propostas de atividades nessa linha.

A avaliação foi realizada a partir da participação nos projetos e no desenvolvimento das atividades propostas de forma bastante processual. Como os alunos estiveram, em grande medida, atuantes no curso pudemos 
ver a desenvoltura e o amadurecimento de quase todos durante os desafios propostos. Foi realizada ainda uma autoavaliação com a intenção de gerar um processo avaliativo completo no qual o próprio aluno passou a ser protagonista do percurso vivenciado e, por isso, deveria saber em que medida foi bem e onde poderia melhorar.

Outro aspecto relevante se refere à noção de que o Design está não só nas técnicas, mas na abordagem, na perspectiva, no olhar para o público e no envolvimento cuidadoso de uma ação pedagógica instigante. Desta percepção surgiu o termo Professor-Designer de experiências de aprendizagem. Esse olhar de quem planeja experiências de aprendizagem revela opções e até mesmo um discurso político: o quanto é importante enquadrar o discurso pedagógico nas questões de identidade, diferença e poder para uma ação pedagógica contemporânea, uma vez que já sabemos que as linguagens, estéticas e estratégias planejadas implicam também em opções éticas.

A docência, vista como um exercício de invenção, permite trânsitos e experimentações que nada tem a ver com a fixidez das técnicas de aprenderensinar que nos apresentaram como 'as mais eficientes' para tal público ou assunto. A experimentação de linguagens e o reconhecimento de que muitas são as formas de expressão possíveis na sala de aula nos leva a pensar no quão imperativo é fazer valer a negociação, a tradução e a hibridização (BHABHA, 1998) entre perspectivas e discursos, inclusive aqueles produzidos em contextos não-científicos, como a literatura, o cinema, os ditados populares, a fotografia, as artes, as mídias e as falas das ruas, entre outros.

Como concebidas por Bhabha (1998), traduções, negociações e hibridizações são operações que se engendram nos cruzamentos entre fronteiras culturais, podem ser tanto consensuais como conflituosas, mas produzem sempre a diferenciação como condição e processo. Na feitura de um trabalho em grupo, há toda uma dinâmica de convencimentos, distribuição de tarefas, estabelecimento de prazos e demais trilhas a seguir rumo ao objetivo final (ao menos nos trabalhos em grupo que, de fato, funcionam coletivamente). Nesse encontro de individualidades, pode ocorrer o choque, a hibridação, a mudança de perspectiva ou a emergência da indiferença. Não é preciso muito esforço para entender que essa terceira possibilidade é menos desejável para uma sala de aula.

Por fim, verificamos que uma experiência em que há uma proposta lúdica que ocorre com a mobilização de diferentes recursos didáticos e estratégias de comunicação atinge os alunos respeitando suas diferenças e preferências. Cada um aproximou-se dos assuntos discutidos e propostas realizadas instigado por recursos diferentes. Ou seja, quando diversificamos as estratégias lúdicas, didáticas e formas de comunicação, verificamos que conseguimos atingir pessoas de perfil muito singulares. Podemos dizer que planejamos e conseguimos realizar um incremento de possibilidades de atrair a atenção e a motivação dos estudantes para o conhecimento colaborativamente construído.

\section{Considerações finais}

Consideramos, então, ser fundamental pensar no professor fazedor como sendo um profissional que cria seu próprio material (dinâmicas, artefatos culturais, mediações, desafios e etc.), dando aos seus recursos de aula uma assinatura que fale dele mesmo, do seu tempo e que acima de tudo converse com os saberesfazeres de suas turmas. O professor designer de experiências de aprenderensinar, mais que um propositor de atividades, é um mediador entre o estudante e as formas de produzir conhecimentos, alguém que estimula autorias múltiplas e plurais e que não se contenta com respostas fáceis. Trata-se de um fazedor de perguntas, de um artesão de tecnologias educativas.

\section{Notas}

1. Fazedor possui aqui uma função adjetiva, visando marcar o aspecto mão na massa que consideramos ser parte importante das autorias docentes. A ideia de 'artífice' de Richard Sennett (2009) também nos inspira na elaboração do 'professor fazedor'. O artífice é o profissional que se dedica à arte pela arte. Seu trabalho não se submete ao tempo, mas ao prazer da feitura; ele "representa uma condição humana especial: a do engajamento" (p.30). 
2. RPG é uma abreviação de Role Playing Game, ou "Jogo de Interpretação de Papéis/Personagens", em português. Pode ser jogado com muitos participantes e aos jogadores é dada a oportunidade de traçar o perfil dos personagens que interpretarão. Os jogos de RPG são conduzidos por um Mestre, responsável por 1) costurar as narrativas criadas colaborativamente e também 2) verificar se as ações praticadas foram bem sucedidas ou não. $\mathrm{O}$ Mestre não age arbitrariamente, mas guiado por um sistema de regras previamente apresentado a todos. Há sistemas de RPG cujas partidas duram 40 minutos. Há outros que podem chegar a 5 horas ou mais, dependendo da disposição física e mental dos jogadores.

\section{Contato dos autores}

Bianca Martins | maildabia@gmail.com

Leonardo Nolasco-Silva | leonolascosilva@gmail.com

\section{Referências Bilbiográficas}

ALVES, N. Trajetórias e redes na formação de professores. Rio de Janeiro: DP\&A, 1998.

A experiência da diversidade do cotidiano e suas consequências na formação de professores. In: FILHO, Aldo Victorio; MONTEIRO, Solange Castellano Fernandes (Orgs.). Cultura e conhecimento de professores. Rio de Janeiro: DP\&A, 2002, p.13-30

Cultura e Cotidiano Escolar. In: Revista Brasileira de Educação. Mai./Jun./Jul./Ago. 2003, n 23.

Praticantepensante de cotidianos. Organização e introdução Alexandra Garcia, Inês Barbosa de Oliveira; textos selecionados de Nilda Alves. Belo Horizonte: Autêntica Editora, 2015.

Decifrando o Pergaminho - o cotidiano das escolas nas lógicas das redes cotidianas. In: OLIVEIRA, Inês Barbosa de; p. 13-38

BHABHA, H. K. O local da cultura. Belo Horizonte: Editora UFMG, 1998.

CERTEAU, M. A Invenção do Cotidiano: 1. Artes de Fazer. Petrópolis, RJ: Vozes, 1994.

LAWSON, B. Como arquitetos e designers pensam. São Paulo: Oficina de textos, 2011.

KASTRUP, V. Políticas cognitivas na formação do professor e o problema do devir-mestre. In: Educ. Soc., Campinas, vol. 26, n. 93, p. 1273-1288, Set./Dez. 2005.

MARTINS, B. M. R. O professor-designer de Experiências de aprendizagem: Tecendo uma epistemologia para a inserção do Design na Escola. 2016. Tese (Doutorado em Design) - Departamento de Artes e Design - Pontifícia Universidade Católica do Rio de Janeiro, PUC-Rio, Rio de Janeiro, Brasil. 2016.

MORIN, E. Introdução ao pensamento complexo. Porto Alegre: Sulina, 2007.

SENNETT, R. O Artífice. Rio de Janeiro; São Paulo: Editora Record, 2009. 